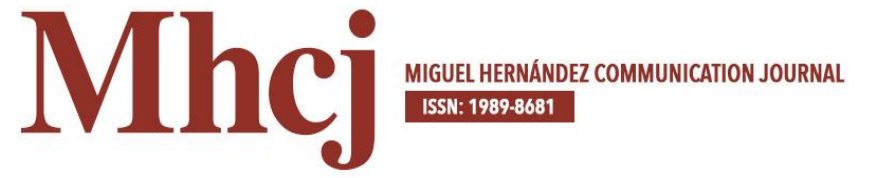

\title{
Impresiones sobre Carne y Arena: práctica cinematográfica y realidad virtual
}

\author{
Dr. Francisco Julián Martínez Cano| francisco.martinezc@umh.es \\ Universidad Miguel Hernández
}

Palabras clave

Audiovisual; Cine; Inmersión; Mixmedia;

Narrativa; Realidad virtual; Videojuego

Sumario

1. Introducción. 2. Metodología. 3.

Resultados. 3.1. Descripción. 4. Discusión. 5.

Conclusiones. 6. Bibliografía

\section{Resumen}

Los productos audiovisuales han ido evolucionando de la mano de los avances tecnológicos. Desde finales del siglo XIX, diversos artilugios y parafernalias técnicas han hecho posible el uso de imágenes en movimiento para contar historias, impulso inherente de la naturaleza humana. En el momento actual, somos testigos de la aparición de las técnicas e instrumentos de realidad virtual para crear experiencias que alcanzan niveles de inmersión superiores a las técnicas de construcción del discurso audiovisual convencional. Esta tendencia se nutre de otros productos del medio como son los videojuegos, el arte contemporáneo, la fotografía, la publicidad y la narrativa, entre otros. Dentro de estos nuevos paradigmas encontramos Carne y Arena (2017), del director Alejandro González Iñárritu, una de las últimas propuestas que explora nuevos caminos en cuanto a la creación de experiencias innovadoras a través de discursos narrativos con tecnología de realidad virtual. Este trabajo propone un estudio y análisis de esta pieza, con el objetivo de acercarnos a estos nuevos procesos de creación del discurso audiovisual, tratando de responder las cuestiones que plantean estos nuevos medios.

\section{Cómo citar este texto:}

Francisco Julián Martínez Cano (2018) Impresiones sobre Carne y Arena: práctica cinematográfica y realidad virtual. Miguel Hernández Communication Journal, 9 (1), pp. 161 a 190. Universidad Miguel Hernández, UMH (Elche-Alicante).

DOI: http://dx.doi.org/10.21134/mhcj.v0i9.222 


\title{
Impressions about Carne y Arena: film practice and virtual reality
}

\author{
Dr. Francisco Julián Martínez Cano | francisco.martinezc@umh.es \\ Universidad Miguel Hernández
}

\author{
Keywords \\ Audiovisual; Film; Immersion; Storytelling; \\ Mixmedia; Videogame; Virtual reality \\ Summary \\ 1. Introduction. 2. Methodology. 3. Results. 3.1. \\ Description. 4. Discussion. 5. Conclusions. 6. \\ Bibliography.
}

\begin{abstract}
Audiovisual products have been evolving along with technological advances during the historical development of the human being. From the end of the nineteenth century until the present time, various gadgets and technical paraphernalia have made possible the use of moving images to tell stories, inherent impulse of human nature.

At the moment we are witnessing the emergence of techniques and instruments of
\end{abstract} virtual reality to create experiences that reach levels of immersion superior to the techniques of construction of conventional audiovisual discourse. This trend is nourished by other media products such as video games, contemporary art, photography, advertising and narrative, among others. Within these new paradigms we find Carne y Arena (2017), directed by Alejandro González Iñárritu, one of the last attempts to break down the barriers and explore new ways of producing innovative experiences to create narrative discourses. This work proposes a study and analysis of this piece, with the objective of approaching these new processes of creation of the audiovisual discourse, trying to answer the questions raised by these new media.

\section{How to cite this text:}

Francisco Julián Martínez Cano (2018) Impressions about Carne y Arena: film practice and virtual reality. Miguel Hernández Communication Journal, 9 (1), pp. 161 to 190. Universidad Miguel Hernández, UMH (Elche-Alicante).

DOI: http://dx.doi.org/10.21134/mhcj.v0i9.222 


\section{Introducción}

Durante el primer cuarto del siglo XXI, la construcción del discurso audiovisual comienza a explorar nuevas vías de expresión. La realidad virtual (RV) cuestiona el aparato cinematográfico tal como lo conocemos y desafía el lenguaje audiovisual y su convención a la hora de construir estrategias narrativas. Es importante destacar que desde el 2014 se han llevado a cabo múltiples creaciones, además de producirse diversas experiencias audiovisuales a través del uso de la RV. Es el caso de la película Wild (2014), dirigida por Jean-Marc Vallée y producida por Pacific Standard River, Road Entertainment y Fox Searchlight Pictures, estudio que además desarrolló la secuencia de tres minutos de duración creada por Felix Raphaël y Paul Lajeunesse en la que, a través del dispositivo de RV Samsung Gear, establecen una estrategia narrativa alejada de grandes efectos especiales, pero en la que la técnica en sí genera una verdadera experiencia inmersiva, catapultando al espectador dentro de la propia secuencia, como individuo partícipe de los acontecimientos que suceden, abordando el término presencia, concepto estudiado por diferentes investigadores (Heeter, 1992; Held y Durlach, 1992; Loomis, 1992; Sheridan, 1992; Steur, 1992; Barfield y Weghorst, 1993; Barfield y Hendrix, 1995; en Slater, Steed y Usoh, 2013: 8), y que alcanza en este tipo de obras su máxima expresión. Se define pues como "un estado de conciencia, el sentido (psicológico) de estar en el entorno virtual" (Slater y Wilbur, 1997). Del mismo modo, la presencia requiere de la capacidad de interacción por parte del usuario:

The argument is that reality is formed through actions, rather than through mental filters and that "...the reality of experience is defined relative to functionality, rather than to appearances". The key to this approach is that the sense of 'being there' in a $\mathrm{VE}$ is grounded on the ability to 'do' there (Sánchez-Vives y Slater, 2005). 
La inmersión es junto a la presencia, uno de los factores clave en los procesos de creación de experiencias audiovisuales con RV. Según Slater y Wilbur (1997), la inmersión se define como:

La medida en que las pantallas de la computadora son capaces de generar y entregar al usuario, a los sentidos del participante, una ilusión inclusiva, extensa, circundante y vívida de la realidad (1997: 606).

A este respecto, los registros audiovisuales 360, combinados con entornos y recreaciones tridimensionales a través de motores de videojuegos, son capaces en la actualidad de propiciar la inmersión del espectador a través de dispositivos de RV.

Al mismo tiempo, es necesario entender la RV más allá del conjunto de dispositivos o hardware necesario para su distribución y consumo y, comenzar a definirla como la creación de experiencias inmersivas. Según Jonathan Steuer:

Virtual reality (VR) has typically been portrayed as a medium, like telephone or television. This new medium is typically defined in terms of a particular collection of technological hardware, including computers, head-mounted displays, headphones, and motion-sensing gloves. The focus of virtual reality is thus technological, rather than experiential; the locus of virtual reality is a collection of machines. Such a concept is useful to producers of VR-related hardware. However, for communication researchers, policy makers, software developers, or media consumers, a device driven definition of virtual reality is unacceptable: It fails to provide any insight into the processes or effects of using these systems, fails to provide a conceptual framework from which to make 
regulatory decisions, fails to provide an aesthetic from which to create media products, and fails to provide a method for consumers to rely on their experiences with other media in understanding the nature of virtual reality (Steuer, 1993: 4).

Los nuevos discursos audiovisuales a través de RV se articulan desde el concepto de experiencia, en el cual la presencia es uno de los pilares para este tipo de producciones audiovisuales, más allá de la apariencia a través del visionado de imágenes. Los modos de actuar dentro de estos entornos virtuales, dentro del contexto de la producción cinematográfica con el uso de $\mathrm{RV}$, se componen de sistemas de interacción en los que la audiencia puede ser consciente totalmente de su intervención, a través de una interfaz objetual como puede ser un gamepad, o no, interactuando de un modo inconsciente, guiado por la dirección de la atención de la propia pieza, a través de un impulso sonoro, un input visual o de algún elemento o actor que forme parte del propio discurso y se configure a partir de inteligencia artificial. A estos tipos de interacción la hemos definido como sistemas de interacción sutil (Martínez Cano, 2016).

La RV en el contexto de la práctica cinematográfica, representa uno de los exponentes actuales del mito del cine total expuesto por André Bazin, que precede según este en su ideación a los desarrollos técnicos y tecnológicos que lo posibilitan:

Con esta perspectiva resulta absurdo mantener el cine mudo como una especie de perfección primitiva de la que se alejaría cada vez más el realismo del sonido y del color. La primacía de la imagen es accidental histórica y técnicamente; y la nostalgia que mantienen todavía algunos por el mutismo de la pantalla no se remonta demasiado lejos en la infancia del séptimo arte, ya que las verdaderas primicias del cine - que no han llegado a existir más que en la imaginación de algunas decenas de 
hombres del siglo XIX - buscan la imitación total de la naturaleza. Todas las perfecciones que se añadan al cine sólo pueden, paradójicamente, retraerlo a sus orígenes. El cine, realmente, no ha sido inventado todavía (Bazin, 1966: 41).

Por tanto, en esta constante búsqueda de la imitación total de la naturaleza en su registro, el cine con $\mathrm{RV}$ cuenta con nuevos recursos y procesos, capaces de construir un sistema que imite la experiencia natural a partir de la recreación de situaciones y la construcción de narrativas que sumergen al individuo en la propia obra, siendo capaz de hacerle partícipe de los acontecimientos narrados. Nos encontramos todavía en un estadio primigenio del desarrollo de este tipo de experiencia audiovisual, que nos sitúa en el origen de un nuevo medio, nos retrotrae a los orígenes de la imagen en movimiento. No obstante, los primeros proyectos llevados a cabo están alcanzado importantes cotas de inmersión, extrapolando la experiencia audiovisual desde la superficie de la pantalla bidimensional a un sistema que envuelve al espectador y le sitúa en el lugar de la acción. Estos sistemas se nutren de la convergencia tecnológica y de medios, los avances técnicos y su combinación, que hacen posible la construcción de nuevos modelos audiovisuales. A pesar del escepticismo presente todavía en la industria y en la audiencia, estamos ante una nueva forma de construir el discurso audiovisual, asistimos a la creación de una nueva gramática de la imagen en movimiento, que aumenta en cierto modo el realismo de la experiencia cinemática. "Es por lo que resulta inútil oponerse a todo progreso técnico que tenga por objeto aumentar el realismo cinematográfico: sonido, color, relieve.” (Bazin, 1966: 430).

En 2017, el Festival de Cannes ha invitado al director Alejandro González Iñárritu a presentar su última creación, una obra que va más allá de la expresión fílmica tradicional, que aborda y usa diferentes medios, desde la tecnología digital y virtual, la fotografía 360, la instalación y el formato expositivo más cercano a la galería de arte o museo, para componer una obra que traspasa los límites del documental. Se trata de una experiencia que tiene al 
mismo tiempo urgencia política y presenta a su vez avances técnicos significativos a la hora de utilizar las últimas técnicas digitales, pero además nos plantea nuevas cuestiones acerca del futuro de la construcción del discurso audiovisual. El impacto de la RV en el medio audiovisual y, en concreto en el cine, comienza a reflejarse en el paulatino crecimiento del número de obras y creadores que poco a poco se inscriben en el nuevo medio para explorar otros modos de expresión a la hora de narrar acontecimientos, de comunicar y transmitir emociones al espectador que, desde una mirada presente en la escena, incurre en nuevas formas de guiarlo a través del discurso. Los términos inmersión y presencia son dos de los pilares fundamentales a la hora de construir una experiencia con el uso de esta técnica. La inmersión, identificada como una cualidad de la tecnología usada (Sanchez-Vives y Slater, 2005), y la presencia, concepto definido a través de una perspectiva de la percepción humana (Slater, Usoh y Steed, 1994), son usados para definir y medir el sentimiento de "estar alli", estar en un entorno artificial mediado por diferentes soportes.

Además, la academia de Hollywood le ha entregado el Óscar especial por esta obra, según justifica John Bailey, presidente de la Academia:

La junta de gobernadores de la Academia tomó esta decisión

"en reconocimiento a una experiencia narrativa visionaria y poderosa". [...] La junta está orgullosa de presentar este Óscar especial a Carne y arena, en la que Iñárritu y su director de fotografía, Emmanuel Lubezki, nos han abierto nuevas puertas a la percepción cinematográfica (E. E. / Agencias, 2017).

\section{Metodología y objetivos}

Para llevar a cabo este estudio de carácter documental, se ha utilizado la metodología de estudio de casos, aplicado a la última creación audiovisual del director Alejandro González Iñárritu, titulada Carne y Arena (2017), pieza en la 
que convergen diferentes medios, soportes y estrategias para confeccionar una de las primeras experiencias cinematográficas con RV.

El objetivo de este trabajo es analizar la obra presentada como caso concreto y actual en el uso de tecnología de RV para la creación del discurso audiovisual, revisando el método y la construcción del mismo, abordando los medios y técnicas empleados y su efectividad en el proceso comunicativo y las estrategias diseñadas a tal efecto, comparándolo con otros casos concretos dentro del mismo contexto del uso de RV para la creación de productos audiovisuales y, además, identificando las cuestiones que se desprenden de estos productos, los desafíos que presentan para el medio cinematográfico, tanto para el autor como para la audiencia, así como aportar posibles respuestas a estos nuevos supuestos.

Finalmente, la intención es poner de manifiesto la importancia de la experimentación en el uso de estas técnicas de RV, para abordar la producción contemporánea de estructuras narrativas a través de imágenes virtuales, construidas en entornos tridimensionales o a través de registros en video 360, que dan respuesta a la cuestión de la evolución del medio audiovisual y la expresión cinematográfica contemporánea. ¿Hacia dónde se dirige la industria audiovisual?, ¿Qué es lo próximo en el contexto de la práctica cinematográfica?, son algunas de las preguntas que surgen a partir del objeto de estudio. A través de la descripción detallada de la experiencia que plantea esta obra, la revisión de los ámbitos de relevancia y soportes que la integran, así como de la revisión de las fuentes de información relevantes: entrevistas al autor y director, así como textos y críticas en relación a esta obra, trataremos de realizar una aproximación a estas cuestiones.

\section{Resultados}

Se trata de una instalación que el Festival de Cannes 2017 ha solicitado al autor para su montaje, siendo la primera pieza de RV incluida en el festival fuera de 
concurso, presentada dentro de la sección oficial y de las celebraciones del 70 aniversario del evento. El proyecto titulado Carne y Arena (Virtualmente presente, físicamente invisible), tiene una duración de seis minutos y medio, y ha sido producido por Mary Parent y ILMxLAB (https://www.ilm.com/ilmxlab/), y financiada por la empresa Legendary Entertainment (http://corporate.legendary.com/) y la Fundación Prada de Milán (http://www.fondazioneprada.org/). La instalación, concebida fuera de la sala de cine y del espacio donde se celebra el festival, se dispone fuera del aparato cinematográfico por defecto, trasladándose a un hangar del aeropuerto. La experiencia inmersiva está compuesta por un itinerario en tres espacios diferentes, a modo de instalación artística, emulando las condiciones del espacio museístico.

\subsection{Descripción}

La visita a la instalación debe solicitarse a través de la web del festival y de un formulario de inscripción, desde el cual se confirma vía email la hora y el lugar concreto donde se recoge al visitante. Al llegar al lugar donde se ha instalado la obra, lo primero que se encuentra es un muro con el cartel y los textos explicativos de la creación de esta experiencia. Una vez firmado el acuerdo de responsabilidad consciente, previo a la entrada, se accede a un pasillo que conduce a un espacio que simula un contenedor lleno de zapatos que han sido usados por inmigrantes reales. En este espacio se le solicita al visitante que se descalce mientras se espera a que una luz se encienda, permitiendo el acceso al siguiente habitáculo. El segundo espacio al que se accede, es un arenero oscuro, donde solo hay una línea de luz naranja. Al acceder a este espacio, el espectador siente la arena del desierto al tacto con los pies. Una vez dentro, se le coloca una mochila para simular que es un inmigrante, y unas gafas de RV. Una vez sumergido en la pieza, el participante puede caminar y moverse a través del espacio. Al instante, comienza el camino a través de una noche en el desierto, al fondo se vislumbra un grupo de inmigrantes, arranca el camino a través del entorno virtual 3D con soporte de imagen fotográfica digital 360, sintiendo la arena en los pies y el viento del desierto que golpea, simulado a 
través del diseño de sonido. Al fondo, el grupo de inmigrantes continúa, se acercan al usuario, se escuchan los diálogos y las conversaciones, cuando aparece un helicóptero, y una patrulla fronteriza con perros incluidos, donde se vive en directo el trato que reciben los inmigrantes por estos soldados del ejército fronterizo.

La audiencia puede moverse en la escena, está dentro, vive en primera persona como detienen y esposan a los inmigrantes, y en una suerte de flashback, es transportada a escenas de las vidas pasadas de estos personajes, extraídos de eventos reales, cenas familiares y vivencias personales, para ser devueltos de nuevo al desierto, donde uno de los soldados se dirige directamente al espectador, le ordena que se tire al suelo mientras se dispone a detenerlo, es el desenlace de máxima tensión, pero la experiencia todavía no ha terminado. Una vez se accede al tercer espacio, se encuentra un pasillo con los retratos de las personas que participaron en la creación de esta experiencia, con textos biográficos y explicativos de cada uno de ellos, fragmentos de realidad documentados que terminan de narrar la experiencia que trata de construir la obra.

Una vez concluido el itinerario diseñado, se le ofrece al participante un espacio donde tomar un refresco y snacks, un lugar de descanso tras la experiencia inmersiva. La pieza se compone por tanto de la instalación de recepción (contenedor lleno de calzado), la instalación con el audiovisual virtual, donde se recrean las condiciones físicas del desierto a través de la arena, la galería de retratos en formato video y fotográfico donde se accede a los testimonios de las personas que forman el elenco de actores, migrantes reales, y el espacio de descanso final previo a abandonar la instalación, con lo que la temporización de la misma se aproxima a la hora de duración.

De acuerdo con el propio González Iñárritu, Carne y Arena está planteada como una experiencia en tres actos: físico, virtual e intelectual. La primera sala recuerda a las "hieleras", 
habitaciones de detención donde los migrantes capturados pasan hasta dos semanas en condiciones precarias, ahí se vive la fisicalidad de la experiencia. La segunda sala, donde se vive la experiencia de $\mathrm{RV}$, corresponde con la vivencia virtual del viaje a través del desierto. Finalmente, el último espacio apela a la reflexión intelectual pues se tiene acceso a las historias de vida de los migrantes entrevistados a través de retratos en video. "La virtualidad no es suficiente, por eso apelo a la realidad", asegura el cineasta. "Me entristece la coincidencia, pero me alegra que desde esta plataforma humanística se pueda hablar del tema migratorio desde realidades más complejas" (Vargas, 2017).

\section{2 Ámbitos de relevancia}

El caso, una vez definido como obra de arte total, instalación audiovisual de $\mathrm{RV}$, es sin duda alguna un producto innovador cuyos ámbitos de relevancia se inscriben dentro del contexto del espacio expositivo, la instalación escultórica, el producto cinematográfico, la práctica audiovisual, la RV, las técnicas de construcción de imágenes digitales y 3D, la fotografía y el video 360 y las estrategias de marketing y publicidad. Es por tanto una obra mixmedia que se apropia de los recursos de diversas disciplinas para construirse y ser entendida como una experiencia, más allá de la vivencia de asistir a la sala de cine para ver una película o a una galería de arte donde explorar una propuesta expositiva.

A nivel del propio texto en sí, la historia nos sitúa a través de la RV en la situación que viven los migrantes mexicanos que intentan pasar la frontera con EEUU, la emoción y la tensión alcanzadas a través de los medios, tanto digitales como físicos, en este caso la instalación de arena del desierto que pisamos, mientras estamos inmersos en la estructura narrativa, son de gran calado en la audiencia, lo que implica un alto nivel de efectividad en cuanto a 
su intencionalidad comunicadora sobre este conflicto social de nuestro tiempo.

En este conjunto múltiple de variables a tener en cuenta, no se puede obviar el hecho de que González Iñárritu siempre ha creado sus obras desde una perspectiva humanista, siendo uno de los creadores inmersos en la nueva narrativa postmoderna, manejando con maestría el modo de representación institucional (Gómez Tarín, 2003), alternándolo con esquemas fragmentarios y sobre todo trabajando el modelo multitrama, por tanto no es de extrañar que sea uno de los directores que afrontan el reto de la experimentación con nuevas técnicas y nuevos modelos de construcción del storytelling.

\subsection{Análisis e interpretación}

En primera instancia, podría sugerirse que la obra objeto de estudio se enmarca dentro del modo de representación primitivo (M.R.P), "es asimilable al denominado cine de atracciones, de carácter esencialmente mostrativo" (Gómez Tarín, 2003: 653), debido a la técnica utilizada y al carácter efectista que posee el propio medio virtual.

En esta situación "puente", el modelo proveniente del cine de atracciones conserva su vigencia esencialmente en el slapstick, que se continúa posteriormente en la serie de cómicos americanos (CHAPLIN, LLOYD, KEATON, LAUREL Y HARDY, LEWIS) y en el musical, prácticamente hasta nuestros días, tanto más en cuanto que las recientes producciones de éxito comercial basadas en la ciencia-ficción y la realidad virtual remiten, en muchas ocasiones, a esa tendencia circense, espectacular, plagada de persecuciones y donde la trama argumental ha pasado a ser un puro subterfugio, una endeble base de un edifico fragmentario, cada vez más lejos del cine de integración narrativa en el que todos 
los acontecimientos se asientan en una estructura, todas las acciones se articulan hacia una totalidad y existe un cierre del relato (Gómez Tarín, 2003: 659).

Sin embargo, la estructura narrativa que sustenta esta obra la extrae del marco de este modelo. El carácter de documental y el objetivo de crear conciencia en el espectador a través de la experiencia inmersiva que genera, la aparta del concepto de cine de atracciones. No obstante, combina ambos modelos, haciendo uso del planteamiento mostrativo o showing y el discursivo o telling, como estrategias presentes tanto en el MRI como en el MRP, según Tom Gunning y André Gaudreault (2006; en Gómez Tarín, 2008), pero el hecho de ubicar al espectador en el lugar del actor, dentro de la recreación de los acontecimientos, y las posibilidades de este para interactuar, dirigir su atención de forma autónoma e interpretar la pieza desde el lugar de la cámara, genera nuevos modos de entender y crear la diégesis audiovisual. Incluimos esta pieza dentro del ámbito de la narrativa postmoderna, planteando diferentes cuestiones del lenguaje y su convención en relación al punto de vista, la dirección de la mirada, la ocularización y focalización y la relación entre espectador y personaje.

El propio discurso audiovisual con tecnología de RV plantea la necesidad de reformular los conceptos y teorías previos. Gómez Tarín advierte de este fenómeno constante que radica en la evolución continua del medio audiovisual:

[...] primero la modernidad cinematográfica, pero más tarde la publicidad, el video-clip, la video-creación, la animación infográfica, el multimedia, el hipermedia, etc., han desmembrado para siempre el edificio en que se sustentaban las teorías más clásicas y, aparentemente, robustas (Gómez Tarín, 2008: 2). 
El hecho de que el espectador, entendido como usuario, sea partícipe en primera persona del discurrir de la narración, que pueda verse modificada a través de sus reacciones o actos, ya sean conscientes o sutiles, modifica las relaciones entre espectador y personaje. Retomando el concepto de focalización, entendido como saber, y el de ocularización como mirar, diferenciados por François Jost a partir de Gérard Genette (Gómez Tarín, 2008), resulta complejo diferenciar ambos en el contexto del espectadorpersonaje. Hablaríamos por tanto de la fusión de ambas figuras en el contexto del cine virtual, en el que la figura del narrador habitual es desechada con el objetivo de proveer a la experiencia de un mayor grado de inmersión, aunque también puede usarse como recurso, dependiendo de los objetivos comunicativos de la obra. Podríamos atisbar que, a nivel de focalización, dependiendo de la estrategia utilizada, puede variar, pero en la obra objeto de estudio esta sería interna y constante en el tiempo, pudiendo oscilar entre sus diferentes tipos, ya que el mismo usuario, durante los procesos mostrativo y discursivo, accede a ocupar el avatar de diferentes personajes, y por ende su perspectiva o saber. Según formulan Todorov y Pouillon entre otros, citados por José Luis García Barrientos:

Focalización interna, en que el narrador "no dice más de lo que sabe un personaje", de lo que tal personaje puede percibir desde su punto de vista, y cabe relacionar con la fórmula "Narrador=Personaje" de Todorov, la "visión con" de Pouillon, el relato de "punto de vista de Lubbock, el "campo restringido" de Blin o el "tipo actorial" de Lintvelt. Ésta puede ser, a su vez: fija, si se mantiene el mismo personaje como sujeto o conciencia focal a lo largo del relato; variable, si el foco pasa de uno a otro personaje, siempre que cada uno focalice distintos contenidos diegéticos; y múltiple, si distintos personajes se van alternando en la focalización "de una misma historia” (García Barrientos, 1992: 35). 
Sin embargo, aplicar esta clasificación de focalización resulta más apropiada, si entendemos que el usuario juega el papel del personaje y, por lo tanto, en ausencia de un narrador y de una sucesión de planos durante cada secuencia, el saber del que dispone es el que adquiere a partir del propio desarrollo de la experiencia y el del resultado de su participación activa dentro de la misma. Esta cuestión enlaza mejor con la propuesta de Jost (1987) a través del término ocularización (visión), frente al de focalización (saber), ya que ambos conceptos se combinan en el entorno de la experiencia virtual.

Focalización interna indica que nuestro conocimiento de lo percibido es equivalente a lo que de ello tiene el personaje; tal conocimiento se refiere a todo lo que el personaje puede saber: pensamientos, deseos, recuerdos. (Jost, 1987; en Gómez Tarín, 2008: 11).

Del mismo modo, desde el concepto de ocularización, entendemos que en la práctica cinematográfica con $\mathrm{RV}$ el tipo de ocularización existente sería también el interno, puesto que "el espectador se identifica con la mirada de un personaje" (Gómez Tarín, 2006: 115), y dentro de sus variantes, solo puede existir la ocularización interna primaria, puesto que la secundaria es construida por el montaje (Jost, 1987), elemento del que se prescinde en la construcción de secuencias audiovisuales para RV, ya que cada secuencia es un plano fijo 360.

La ocularización es empleada por Jost (1987) “para interpretar la relación entre lo que la cámara muestra y aquello que se supone que ve el personaje" (Gómez Tarín, 2006: 114). Al tratarse pues de una obra audiovisual virtual, el espectador tiene una visión 360 del entorno donde se desarrolla la acción, que funde ambas visiones, siendo él mismo el que explora y establece su propio punto de vista, dirige su atención, en ausencia de ningún input, trigger, inteligencia artificial o estrategia por parte del autor para conducir la visión del espectador durante el desarrollo narrativo. Las marcas enunciativas 
relacionadas con el meganarrador en cuanto a movimientos de cámara desaparecen, mientras que las relaciones imagen, entendida como el entorno 3D o el registro 360, y sonido, saber-visión, presencia-ausencia, son dictadas por el autor, pero no dependen de lo que se encuentra dentro o fuera de plano. Por tanto, la función del director es encontrar nuevas vías de dirigir la atención del espectador durante el discurrir de la narración. Plantea esta cuestión un desafío claro para la construcción de los discursos audiovisuales con RV. En este sentido, y con el fin de alcanzar la inmersión de la audiencia dentro del discurso, principio base de la experiencia virtual, es necesario alcanzar la suspensión de incredulidad por parte del usuario.

Suspension of Disbelief: This term arose from film criticism and is defined as the ability to give in to a simulation-to ignore its medium. The early attempts of the entertainment industry to achieve better suspension of disbelief laid the foundations for current virtual reality research. Suspension of disbelief is a fundamental part of the effective use of a virtual reality interface. Until we can ignore the interface and concentrate on the application, virtual reality will remain a novel experience instead of a serious visualization tool (Cruz-Neira, Sandin, DeFanti, Kenyon y Hart, 1992).

Al mismo tiempo, si revisamos los cuatro paradigmas de la perspectiva del enunciatario según Gaudreault y Jost (1995; en Gómez Tarín, 2008: 7), en el ámbito del audiovisual virtual solo serían posibles los tres primeros supuestos, siendo imposible el cuarto. En relación a la obra objeto de estudio, podríamos indicar el uso de la perspectiva como testigo o visión objetiva de los acontecimientos, además de la perspectiva personaje o visión subjetiva.

En relación al punto de vista, José Prósper Ribes, en su libro El punto de vista en la narrativa cinematográfica (1991), parte de las definiciones clásicas del ámbito literario y las reformula: 
Las diferentes formas de abordar una historia (en la narración) desde diversas opciones (cada una de ellas implica que se muestre algo y, al mismo tiempo, que no se muestre algo), elecciones en la manera en que será mostrada (como serán presentados personajes y acontecimientos) y puntos de observación para organizar las acciones y acontecimientos (Prósper Ribas, 1991: 13).

La historia en definitiva debe aparentar, a ojos del espectador, ser contada por sí misma, lo que implicaría un punto de vista general u objetivo, estructurando la narración y los diversos acontecimientos según lo que la narrativa clásica cinematográfica impone en primera instancia. Pero esto se presupone imposible desde la necesidad de establecer relaciones de empatía entre el espectador y los personajes, y esto normalmente se lleva a cabo a través del uso de la subjetividad, contectando con el saber definido por Jost (1987) a través del concepto de focalización. Desde esta perspectiva, abordando el audiovisual virtual, es posible objetivizar el discurso desde un punto de vista general, si el espectador es un mero visitante de los acontecimientos y no puede participar de ellos, utilizando los recursos narrativos convencionales y extrapolándolos a entornos virtuales que envuelven al espectador, pero en la obra de Iñárritu la subjetividad es uno de los factores clave, a través de la pretensión de hacer al espectador experimentar la vivencia de ser un migrante que trata de cruzar el desierto de Sonora para acceder a los EEUU de manera ilegal. Y en este sentido, la posición de la cámara no es lo verdaderamente importante, puesto que se presupone su ubicación en relación al personaje que va a ser el espectador, y además esta cámara no secciona de modo rectangular lo que se es mostrado, puesto que el campo de visión al que accede el usuario lo envuelve, digamos que la imagen y la acción rodean al espectador, pero la posición de los elementos que componen la acción sí presentan un importante papel, ya no hay interacción entre estos y la cámara, pero sigue existiendo la 
interacción entre lo visual y lo auditivo, además de la interacción entre acción y espectador.

\subsection{Modelo narrativo}

Uno de los paradigmas más significativos de la narrativa postmoderna es el multitrama, multiprotagonista (Orellana y Martínez Lucena, 2010: 244), o también denominado relatos multiplex (Lipovetsky y Serroy, 2009: 102; en Orellana Gutiérrez de Terán, 2012: 1190). El paradigma multitrama, queda definido según: "Películas que reflejan la fragmentación y las nuevas segmentaciones del mundo mediante la heterogeneización estructural y narrativa" (Lipovetsky y Serroy, 2009: 102; en Orellana Gutiérrez de Terán, 2012: 1190). Además, suelen fluir en un devenir de diversas tramas en las que los protagonistas múltiples se entrecruzan, posibilitando ciertos aspectos innovadores, como por ejemplo en cuanto al concepto de identificación por parte del espectador, donde el arco del héroe por antonomasia queda fragmentado también, facilitando la diversidad de identificación de la audiencia según los intereses o gustos individuales de cada espectador. Es palmario que González Iñárritu es uno de los exponentes de esta narrativa postmoderna, reflejado ya en su trilogía Amores Perros (2000), 21 Gramos (2003) y Babel (2006).

En cuanto al modo de cerrar los discursos narrativos en el marco postmoderno, podemos hablar de la desaparición del cierre total, quedando siempre un final que no deja de plantear nuevas cuestiones al espectador. "El desenlace ya no es necesario para el funcionamiento de la película: la imageneficacia se ha apoderado de la sobresaliente función del sentido" (Lipovetsky y Serroy, 2009: 104; en Orellana Gutiérrez de Terán, 2012: 1191). Respecto al modelo de representación institucional, el montaje se centra en contar la historia, para que sea entendida de un modo eficaz y claro. El tratamiento del tiempo y los espacios deben seguir el devenir de los acontecimientos sin más, mientras que los modelos deconstructivos emplean un uso y relación del tiempo y espacio no lineal, a menudo a través del hipermontaje (Gómez Tarín, 
2011: 389-390), creando una percepción más confusa de ambos, una percepción deconstruida e impresionista del film. Es por tanto evidente el uso de González Iñárritu de la multilocalización, el multitrama y los multiprotagonistas en su última creación con RV, condensando la experiencia en tres espacios, plasmando la estructura narrativa en un fragmento corto de duración en la que múltiples actores forman parte de los acontecimientos, generando esa multitrama con los distintos flashbacks que nos llevan al pasado de las vidas de los protagonistas, rompiendo el formato rectangular e introduciendo al espectador como partícipe de los eventos, como uno más de los actores, generando una interconexión más compleja e intensa, difuminando los límites de la ficción, para aportar nuevas esencias al discurso. El desenlace no se cierra por completo, el hipermontaje como estrategia base para la construcción del discurso audiovisual, siendo una pieza en un espaciotiempo virtual discontinuo.

\subsection{Concepto y técnica}

Las reflexiones que parten tanto de la audiencia, la crítica especializada y sobre todo el propio autor en sus declaraciones, nos ayudan a abordar la obra desde una perspectiva próxima, desde la que poder acercarnos a la realidad de estos modos experimentales. Estas aproximaciones nos acercan tanto a lo relativo al concepto de las nuevas obras audiovisuales con RV, como al tratamiento técnico en cuanto lo que esta técnica considerada todavía experimental exige.

André Bazin, desde la perspectiva de un crítico anterior a la revolución digital contemporánea, sugirió que el cambio de paradigma viene designado por el desarrollo evolutivo de las tecnologías y por tanto de las técnicas que se emplean para generar la ilusión cinemática. El gran debate que arranca con la aparición de la RV es si esta va a desbancar a los modos convencionales de crear y consumir cine, al mismo tiempo que otros modelos comerciales se implementan, como es el caso de Netflix, que también aporta al debate la consideración de si realmente las producciones llevadas a cabo por este nuevo 
gigante del audiovisual son verdaderamente cine o simplemente productos televisivos, y evidentemente, los titulares que apuntan a que la RV llega a Cannes 2017, dando a entender que el cine como lo conocemos es una cosa del pasado, no pueden considerarse como correctos, si bien es cierto que somos testigos de la evolución actual del discurso audiovisual desde diferentes enfoques, ya sea desde sus modos de creación o de distribución y consumo. El cine como lo conocemos no está condicionado a desaparecer, en su lugar, a partir de las reflexiones del propio autor sobre estas cuestiones, podemos considerar que la RV no ha venido a sustituir al cine tal y como lo conocemos. En palabras de González Iñárritu:

El cine es encuadre, el cine es longitud de las lentes, el cine es edición, la posición de las imágenes que crean tiempo y espacio. La realidad virtual, incluso cuando es visual, es exactamente todo lo que el cine no es (Kermode y Mayo, 2017).

Estando de acuerdo con esta idea, es importante reseñar que todo el debate que ya surgió con las producciones 3D y el consumo de estos productos en sala, que apuntaban siempre a desplazar el lugar del cine, siendo su interés primigenio diferente en cada uno de los momentos históricos en los que el cine 3D tuvo su incursión, pero siempre luchando contra un competidor, sea este la televisión por cable, el VHS y los videoclubs, o Internet ya en la última década, para recuperar la asistencia de la audiencia a las salas de cine, nunca ha llegado a usurpar el lugar de la ilusión cinemática tal y como la conocemos, quedando simplemente como una nueva opción de crear y consumir contenidos, lo que en la actualidad da lugar a que la gran mayoría de producciones sean filmadas en IMAX 3D para posteriormente tener las dos opciones de consumo, en imagen bidimensional convencional o en 3D estereoscópico. 
Teniendo en cuenta todo esto, lo que la prospectiva indica en primera instancia es que la RV va a convivir como otro nuevo medio de creación, producción y consumo de productos audiovisuales, incluso combinados en una misma obra cinematográfica, como es el caso de Wild (2014), cuya secuencia con RV, Wild, The Experience ( Lajeunesse y Raphaël, 2015), ya impactó en la audiencia del Festival de Sundance en 2015, que acoge en su sección New Frontier proyectos en RV desde el año 2012, en el que Nonny de la Peña presentó su obra Hunger in Los Angeles (2012). Por tanto, también quedan fuera de lugar las afirmaciones en cuanto que esta es la primera vez que se acepta y se muestra un proyecto confeccionado con RV en un festival de cine internacional.

Lo que sí se confirma es el potencial en cuanto a marketing y publicidad se refiere, a la hora de captar la atención del público a través del atractivo de este medio, quizá porque la humanidad lleva fantaseando con estas técnicas y desarrollos tecnológicos durante más de medio siglo, siendo múltiples los investigadores y desarrolladores que ya desde los años 50 y 60 comenzaron a experimentar con los medios que disponían, quizá porque llevamos mucho tiempo esperando y es este el momento en el que la RV irrumpe, gracias a los desarrollos en cuanto a sistemas informáticos y computación se refiere.

Otro ejemplo destacado del uso de RV para la creación de una obra transversal dentro del universo ficcional de una película es el caso de Notes on Blindness (Spinney y Middleton, 2016), para la que crearon también unas secuencias con tecnología virtual, dando la opción a la audiencia de las salas de cine de poder disfrutar de esta experiencia simplemente colocándose un headset o lentes, obteniendo una respuesta positiva, pudiéndose catalogar como una pieza reclamo al igual que en el caso de Wild (2014). En el caso de Carne y Arena (2017), la obra diverge de las anteriores en tanto que no es un fragmento o contenido extra a la película, sino que la pieza está construida íntegramente para ser visualizada con unas lentes RV, sin embargo, sí que atiende a los mismos criterios de uso y empleo de esta tecnología como reclamo comercial, 
habiendo sido una de las piezas más comentadas y trendy de la pasada edición del Festival de Cannes.

A la pregunta de ¿Es el nacimiento de la RV el siguiente gran avance o logro artístico?, es patente que estos nuevos lenguajes ya están comenzando a dar lugar a nuevos tipos de experiencia audiovisual y nuevos medios de expresión artísticos, pero no deben ser tratados como una amenaza para el cine o ninguno de los medios de expresión conocidos hasta la fecha. Es un medio diferente al cine, dentro del audiovisual, que puede convivir con la experiencia cinematográfica de la cual necesita beber y obtener recursos para generar su propia convención del lenguaje audiovisual virtual.

En el caso de Carne y Arena (2017), el elenco de actores se nutre de inmigrantes reales que han colaborado con González Iñárritu durante los cuatro años de gestación de esta obra, sus interpretaciones fueron grabadas en estudio con un complejo sistema de sensores y luego agregados de manera digital al entorno, creado a partir de las fotografías realizadas por Emmanuel Lubezki, director de fotografía y colaborador asiduo del director mexicano. Los avances tecnológicos y la arena bajo tus pies construyen un modelo que realmente transporta al individuo a la experiencia que propone, que en palabras del propio González Iñárritu, no se trata de un posicionamiento político sino más bien humano:

[...] La obra ha sido creada en realidad virtual para tener un gran impacto en una sociedad cada vez menos sensible a imágenes sobre dramas como el de los inmigrantes. [...] La realidad ya no es suficiente para nosotros. La cantidad de información sobre esas personas ya no nos genera ningún interés. Hubiera podido filmar un corto de diez minutos y nadie hubiera venido, lo hubieran visto diez personas. [...] Aquí estoy yo, es una pieza mía, una instalación, es una forma que es una expresión personal de una situación mundial y la 
herramienta tecnológica da la posibilidad, te deja entrar al subconsciente inclusive de los personajes (García, 2017).

La intención de González Iñárritu, más allá de los esteticismos que nunca han sido característica de su obra es, según el mismo autor, experimentar y explorar la condición humana a través del uso de la tecnología, remarcando la necesidad de volver a aprender técnicas de iluminación y adaptarse al hecho de la ruptura de la gramática sujeta a la pantalla rectangular del cine, donde la secuencia tradicional desaparece y el punto de vista del espectador es totalmente libre, generando experiencias individualizadas en cada conciencia.

En cuanto al uso de la cámara, una de las marcas de identidad de este director en cuanto a las coreografías de la cámara en relación a la acción que registran, como es el caso de la secuencia del ataque del oso en The Revenant (2015), donde el fusil sale del plano por la derecha para volver a aparecer por la izquierda en el momento en el que el animal carga su ataque, ponen de manifiesto la influencia del videojuego y sus sistemas de cámara virtuales y de planos subjetivos en la obra de González Iñárritu. La coreografía de la acción se encuentra relacionada directamente con la coreografía de los operadores de cámara y el resto de figuras técnicas que realizan el registro de la acción, promulgando la idea de interdisciplinariedad, como se indica en el texto On collaboration and interdisciplinarity: Meshes of the afternoon (James, 2013), al revisar la obra de Maya Deren (1943) y sus estrategias colaborativas con un enfoque interdisciplinar. En el caso de la obra Carne y Arena (2017), el aparato virtual te invita a ser el director de fotografía, al mismo tiempo que te envuelve en una idea de danza del espectador e interacción dentro del entorno recreado. En este contexto, se pueden establecer conexiones entre la coreografía fílmica y de la acción filmada con Babel (2006) o The Revenant (2015), aunque el largometraje más afín es Birdman (2014), donde la cámara recorre un teatro de Broadway y establece un falso plano secuencia durante toda la película, más cercano a la relación espacial que la RV necesita. El sonido, la ambientación, 
los encuentros físicos vienen a ser los nuevos recursos de construcción al tratarse de una nueva forma de registrar y editar la imagen en movimiento.

Otro de los condicionantes de esta obra es el modo de consumo, al tratarse de una instalación no permite ser visionada por grandes cantidades de público, lo que restringe en gran medida su distribución. Este aspecto cuestiona el modo convencional de acceso a las obras cinematográficas, planteando nuevos esquemas y estrategias de creación de las mismas, basadas en la interdisciplinariedad como pilar fundamental en su construcción. La obra durante el festival fue vista por alrededor de unas 700 personas en sus 11 días de duración, lo que implica la dificultad a la hora de ser exhibida. En términos de este problema, quizá sea necesario abordarlo como una oportunidad, una manera más íntima de acceder a la obra audiovisual, de consumirla de primera mano, pero también la hace más exclusiva, donde la extensión temporal durante la cual está abierta al público es un factor clave para hacerla accesible a la audiencia global. También porque obliga al espectador a trasladarse al espacio in situ donde la obra está instalada, en conexión directa al concepto escultórico y de monumento, en contraposición al momento actual, en el que el individuo está acostumbrado a acceder a los contenidos audiovisuales en cualquier lugar, a través de sus dispositivos móviles conectados a Internet.

\section{Discusión}

Indudablemente, la potencia de discurso de esta obra emerge de las historias reales de sus actores, y aunque es una obra de ficción, amplifica una serie de recursos poéticos que lo hacen mucho más una reflexión acerca de la crisis del ser humano, más allá de entidades documentales sobre las tragedias de nuestro tiempo. Al mismo tiempo, el uso de la RV para construir el discurso audiovisual intensifica la emoción y genera una experiencia más allá del montaje en soporte pantalla. 
Técnicamente es una pieza bien ejecutada, a pesar de la limitación del medio en el momento actual, pero han presionado los medios técnicos hasta culminar con una obra que abre la puerta a un nuevo medio de expresión. Queda definido como un híbrido entre cine, videojuego y realidad, usando un software que permite a la propia obra interactuar con el espectador, conociendo en todo momento la patrulla fronteriza el lugar donde nos encontramos, dirigiéndose directamente a ti y dándote órdenes. Se respira la tensión de la situación, en un medio que nos inquieta y nos sumerge completamente en la experiencia vital que nos presenta. Se produce el intercambio entre visión y experiencia, disolviendo la dualidad entre lo real y lo virtual.

Presenta por tanto una revolución en el ámbito de la comunicación, que se transforma y evoluciona en un modo de sentir, en una manera de interactuar con la imagen en movimiento, la dirección del punto de vista en un soporte cuadrangular evoluciona a una inmersión total de los sentidos. Trasciende el cine, siendo otra entidad completamente distinta, que comienza a convivir con los largometrajes convencionales. En la RV prima el espacio y la atmósfera en contraposición a la importancia de la cámara y su mirada en el contexto de la práctica cinematográfica. También se puede entender como una nueva estrategia para captar audiencia a las salas en pugna con los nuevos competidores, del mismo modo que el cine 3D estereoscópico fue utilizado en momentos de pérdida de audiencia por parte del aparato cinematográfico respecto a nuevos medios de distribución como eran la televisión en la década de los 50 y 60, el video VHS en los 80 y 90, e Internet a principios del siglo XXI, que actualmente da lugar a los gigantes de la distribución online de productos audiovisuales de entretenimiento como son Netflix, Amazon y $\mathrm{HBO}$.

\section{Conclusiones}


En conclusión, la RV apunta sin duda a un futuro cercano, donde no veremos las películas únicamente de un modo pasivo, sino que también tendremos la posibilidad de estar dentro de ellas, experimentando historias de un modo nunca antes explorado. De esta manera, siendo la RV mucho más radical que el cine, es necesario tener algo que ofrecerle a esta técnica, que requiere y necesita mucho más que el medio cinematográfico. No sirve cualquier argumento, ni tampoco pensar en imágenes construyendo secuencias, es necesario diseñar el camino que el individuo ha de recorrer, guiarlo a lo largo de la estructura narrativa, una estructura que necesita ser repensada, siendo la interacción del usuario la pieza clave, la cámara se viste de espectador, nos sitúa dentro de la propia imagen. Aquí es donde reside el poder de Carne y Arena (2017), obligando al espectador a tomar decisiones de un modo activo, a vivir la experiencia de un modo directo, según la leyenda de la propia obra: Virtualmente presente, físicamente invisible.

\section{Referencias bibliográficas}

Barfield, W., y Weghorst, S. (1993). The sense of presence within virtual environments: A conceptual framework. En G. Salvendy y M. J. Smith (Eds.), Human-Computer Interaction: Software and Hardware Interfaces, Proceedings of the Fifth International Conference on Human-Computer Interaction, (HCI Inernational '93), Orlando, Florida, USA, August 8-13, 1993, Volumen 2 (pp. 699-704). Amsterdam: Elsevier.

Barfield, W., y Hendrix, C. (1995). The effect of update rate on the sense of presence within virtual environments. Virtual Reality, 1(1), pp. 3-15.

Bazin, A. (1966). ¿Qué es el cine? Madrid: Rialp.

Cruz-Neira, C., Sandin, D. J., DeFanti, T. A., Kenyon, R. V., y Hart, J. C. (1992). The CAVE: audio visual experience automatic virtual environment. Communications of the ACM, 35(6), pp. 64-73. 
E.E. /Agencias. (27 de octubre, 2017). La Academia entrega un Óscar especial a Iñárritu por su obra en realidad virtual. El Español, España. Recuperado de https://goo.gl/rZGGaT [Recuperado 05/09/2017].

García Barrientos, J. L. (1992). Problemas técnicos de la focalización narrativa (Para una teoría «general» de la focalización). Tropelías, 3, pp. 33-52.

García, E. (18 de mayo, 2017). Asombra González Iñárritu con realidad virtual en Cannes. Diario Tijuana, México. Recuperado de https://goo.gl/Xi55wK [Recuperado 12/08/2017].

Gaudreault, A., y Gunning, T. (2006). Early cinema as a challenge to film history. En W. Strauven (Ed.), The cinema of attractions reloaded (pp. 365-380). Amsterdam: Amsterdam University Press.

Gómez Tarín, F. J. (2003). Lo ausente como discurso: elipsis y fuera de campo en el texto cinematográfico. (Tesis doctoral). Universidad de Valencia, Valencia, España.

- (2006). El análisis del texto fílmico. Castellón: Beira Interior. - (2008). Saber y mirar: una propuesta de reformulación de los conceptos de focalización y ocularización en los discursos audiovisuales. En Investigar la comunicación $=$ investigar a comunicación $=$ investigar la comunicació $=$ komunikazioikerketa: actas y memoria final del Congreso Internacional Fundacional AE-IC, Santiago de Compostela 30, 31 de enero y 1 de febrero de 2008. Santiago de Compostela: Asociación Española de Investigación de la Comunicación. - (2011). Elementos de Narrativa Audiovisual: expresión y narración. Santander: Shangrilá Ediciones.

Heeter, C. (1992). Being there: The subjective experience of presence. Presence: Teleoperators \& Virtual Environments, 1(2), pp. 262-271. 
Held, R. M., y Durlach, N. I. (1992). Telepresence. Presence: Teleoperators \& Virtual Environments, 1(1), pp. 109-112.

James, A. (2013). On Collaboration and Interdisciplinarity: Meshes of the Afternoon. The International Journal of Screendance, 3, pp. 38-52.

Jost, F. (1987). L’Oeil-Caméra. Entre film et roman. Lyon: P.U.L. - y Gaudreault, A. (1995). El relato cinematográfico. Barcelona: Paidós.

Kermode, M. y Mayo, S. [kermodeandmayo]. (31 de mayo, 2017). Kermode Uncut: Virtual Reality In Cannes [Archivo de video]. Recuperado de https://youtu.be/cAFhIlQOrqE [Recuperado 15/08/2017].

Lipovetsky, G. y Serroy, J. (2009). La pantalla global. Cultura mediática y cine en la era hipermoderna. Barcelona: Anagrama.

Loomis, J. M. (1992). Distal attribution and presence. Presence: Teleoperators \& Virtual Environments, 1(1), pp. 113-119.

Martínez Cano, F. J. (2016). Cine, videojuegos y realidad virtual: Estudio y prospectiva del medio audiovisual en la era digital. (Tesis doctoral). Universidad Miguel Hernández, Elche, España.

Orellana Gutiérrez de Terán, J. (2012). Las mixtificaciones narrativas en el cine de Alejandro González Iñárritu. En V. Guarinos y M. J. Ruiz (Eds.), I Congreso Internacional de la Red Iberoamericana de Narrativas Audiovisuales (Red INAV). Málaga-Sevilla, 23-25 de mayo de 2012 (pp. 1189-1200). Sevilla: Universidad de Sevilla, Secretariado de Recursos Audiovisuales y Nuevas Tecnologías. - y Martínez Lucena, J. (2010). Celuloide posmoderno. Madrid: Ediciones Encuentro. 
Ribes, J. P. (1991). El Punto de vista en la narrativa cinematográfica: lección magistral leída en la apertura del curso 1991-1992. Valencia: Fundación Universitaria San Pablo CEU.

Sanchez-Vives, M. V., \& Slater, M. (2005). From presence to consciousness through virtual reality. Nature Reviews Neuroscience, 6(4), pp. 332-339.

Sheridan, T. B. (1992). Musings on telepresence and virtual presence. Presence: Teleoperators \& Virtual Environments, 1(1), pp. 120-126.

Slater, M., Steed, A., \& Usoh, M. (2013). Being there together: Experiments on presence in virtual environments (1990s). London: University College London, Department of Computer Science.

Slater, M., Usoh, M., \& Steed, A. (1994). Depth of presence in virtual environments. Presence: Teleoperators \& Virtual Environments, 3(2), pp. 130-144.

Slater, M., \& Wilbur, S. (1997). A framework for immersive virtual environments (FIVE): Speculations on the role of presence in virtual environments. Presence: Teleoperators and virtual environments, 6(6), pp. 603-616.

Steuer, J. (15 de octubre, 1993). Defining virtual reality: dimensions determining telepresence. Social responses to communication technologies, Paper \#104, EEUU. Recuperado de https://goo.gl/9nCrcV [Recuperado 22/08/2017].

Vargas, M. (2017). Carne y Arena: Vivir la migración hasta los propios huesos. Gatopardo, México. Recuperado de https://goo.gl/heJv1W [Recuperado 19/08/2017]. 


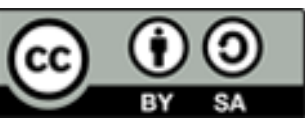

Licencia Creative Commons

Miguel Hernández Communication Journal

mhjournal.org

\section{Cómo citar este texto:}

Francisco Julián Martínez Cano (2018) Impresiones sobre Carne y Arena: práctica cinematográfica y realidad virtual. Miguel Hernández Communication Journal, 9 (1), pp. 161 a 190. Universidad Miguel Hernández, UMH (Elche-Alicante).

DOI: http://dx.doi.org/10.21134/mhcj.v0i9.222 